\title{
Enterprise Energy Management from a Practical Perspective: A Case Study of Anyang Iron and Steel Enterprise
}

\author{
Zhang Menghao ${ }^{1,}$, Zhuo Lihua ${ }^{2, b}$ \\ ${ }^{1}$ Lecturer, Department of Management Engineering, Zhengzhou University, Zhengzhou 450001, China \\ ${ }^{2}$ Lecturer, Department of Information Management, Henan Light Industry Vocational College, Zhengzhou \\ 450001, China \\ a zhangmhyy@163.com, bingyi1988@qq.com
}

Keywords: Energy saving; Energy management; Case study

\begin{abstract}
With the rapid development of "The Belt and Road Initiative", China has made many improvements in cutting overcapacity and increasing the energy efficiency. As a result, the successful and effective practices of energy management and energy conservation and emission reduction of some Chinese enterprises can be beneficial for other countries along the Belt and Road to learn and use for reference. In this sense, this paper studies the enterprise energy management practice by studying and analyzing the example of Anyang Iron and Steel Enterprise. In the study, five subsystems including energy policy and objectives, energy management structure, consciousness of energy saving, energy information management and management practice in process level and three energy-saving methods consisting of technical method, managerial method and structural method are studied in details in order to understand the real situation of energy management practice in the iron and steel firm. Based on the above, it also summarizes ten useful industrial energy management principles. As a result, this study of energy management practice, on one hand, offsets the lack of literature review to some degree, on the other hand, it summaries the experience and principles of energy management in Anyang Iron and Steel Enterprise benefiting for other enterprises to learn from and make future improvements.
\end{abstract}

\section{Introduction}

Due to the fact that contradiction between energy supply and demand and problem between energy and environment become increasingly serious, it is important to pay more attention on the corporate energy management which can be seen as a very useful way to achieve energy saving and emission reduction. As pointed out by Norland and Lind in their survey study, energy management on one hand can be effective to reduce costs of energy use and increase the company performance, on the other hand, is significant to ensure the energy supply and enhance the enterprise competitiveness (Norland and Lind, 2001). Claimed by Caffal, companies in the survey can gain about $40 \%$ cut on cost of energy use by energy management (Caffal, 1995). Also, based on the study on 118 EU enterprises, Wagner finds out that 29.7\% enterprises did the energy management and above $90 \%$ of them realize the growth of benefits (Wagner, 2008). Besides, iron and steel industry, a very important raw material production and process department, which is regarded as the national basic industry and plays a huge role in the stability and sustainable development of national economy, is badly in need of energy management. According to the national statistical yearbook data, in 2013, Chinese output of pig iron, crude steel and steel are 708970, 779040 and 1067620 thousands tons respectively, which are nearly half of the output of the world. However, the Capacity utilization in iron and steel industry is only $78.2 \%$ along with annual rise of energy consumption which now accounts for $15 \%$ of total energy consumption of the national industrial system. Hence, it is essential to study and impel the energy management in iron and steel industry. In light of the giant function and important meaning of energy management for iron and steel enterprise, this article is in use of Anyang iron and steel industry as a case study to analyze the gain and loss of energy management from management practical point of view. By summarizing the successful 
experience and analyzing improvement measures, this article aims to provide some useful thoughts and suggestions for the practice and development of energy management in iron and steel enterprise.

\section{Literature review and Methodology}

Enterprise energy management has been given extensive attention to by scholars for its meaningful importance. Recently, the new focuses in this study area are to use questionnaire inquiry or do case study. By studying and analyzing the enterprise energy management from practical perspectives, the real situation and gain and loss can be found out and summarized in order to understand more about the whole system and make improvement on energy management. Generally, questionnaire inquiry mainly focuses on the study of obstacles and motivations (Christoffersen et al., 2006; Thollander and Ottosson, 2008; Trianni et al, 2013). Under this circumstance, many scholars make further discusses on the major influence factors promoting the enterprise energy management, such as energy price, the cost of energy consumption, the support from top of the enterprise and long-term energy strategy (Rohdin et al. ,2007; Thollander et al., 2007; Cagno and Trianni ,2013). In addition, besides the questionnaire inquiry, many scholars are in favour of case study for it can investigate successful experiences and drawbacks and explore the solutions for practical problems in the enterprise energy management (Sivill et al.,2013; Brunke, Johansson and Thollnder,2014). According to the case study of energy management in 3M company made by Schultz and Bingham, efficient energy management is attributed to the combination among commitment from top management, long-term adaptable energy strategy planning, adequate resources priority and guarantee and active participation on energy conservation projects (Schultz and Bingham, 2000). Based on the case study of energy management in a bakery, Kannan and Boie compares the energy consumption before and after using energy management and proves its importance for small enterprises (Kannan and Boie, 2003). Moreover, Rudberg, Waldemarsson and Lidestam takes Swedish Perstorp AB as an example to explore the practical situation of energy management and discuss ways to improve energy management from enterprise strategically level(Rudberg, Waldemarsson and Lidestam, 2013).

In brief, literature has proved the significance of case study on energy management and has shown plenty achievements of researches on the enterprise energy management from practical analysis. Consequently, by using case study method, this paper analyzes the energy management of Anyang Iron and Steel Enterprise in details. In fact, getting the energy management system certification in 2014 made by Beijing Grand Honour Management System Certification Company, this enterprise is in the advanced position of whole industry in China including its capacity, revenue and energy management. As a result, its typicality makes it more meaningful to study and to be used for reference by other iron and steel enterprises. Accordingly, the case study in this paper is divided into four steps. First of all, a site visit and a meeting with managing director have been made to get an overall understanding of ideas, status and measures of energy management in Anyang Iron and Steel Enterprise. Then, investigation and survey are used to collect main parameters and applications and measures of energy management from the enterprise's internal personnel and information. Third phase includes a detailed interview with the energy environmental manager to discuss the preliminary analyzing results. In the end, information and data are summarized and analyzed from multiple levels and angles to conduct a comprehensive in-depth research.

\section{Energy management in Anyang Iron and Steel Enterprise}

\subsection{Basic information of Anyang Iron and Steel Enterprise}

Case description: Founded in 1958, Anyang Iron and Steel Enterprise is seen as an oversize enterprise combining coking, sintering, smelting, rolling and research development together with four subsidiaries and 20748 employees. In 2013, Anyang Iron and Steel Enterprise is the biggest iron and steel company in Henan Province, 12th of national steel production and 33th of world steel 
production with 10 million tons output and 50 billion revenues. Now, its production contains coking chemical products and 30 varieties and 2000 specifications of steel products such as thick plate, high speed wire and small and medium-sized proximate matter. "To create wealth return for society and make benefits for employees" is the enterprise tenet. Under this situation, Anyang Iron and Steel Enterprise uses "go beyond oneself and work together" as its corporate philosophy and "enterprising professional dedication" as its enterprise spirit aiming to achieve the business goal "the best in the central area and first class in the country".

Case analysis: In the first place, as one oversize enterprise, Anyang Iron and Steel Enterprise is accessible to sufficient capital which leads to better adoption of energy-saving technologies and construction of energy management equipment. Meanwhile, attaching great importance to building enterprise culture and value, the enterprise has made a good foundation for carrying out energy management. Besides, its high capacity also results in scale effect for enterprise energy management. In this sense, it can be said that Anyang Iron and Steel Enterprise has a good foundation for energy management and is worth studying.

\subsection{Guideline, targets and solutions of energy management in Anyang Iron and Steel Enterprise}

Case description: Energy saving has been considered as a significant part of enterprise development strategy and business policy by Anyang Iron and Steel Enterprise. As a result, the enterprise's guiding thought for energy management policy is "to make a solid foundation, to improve level by level and step by step, and to implement the energy management scientifically". Also, the energy management guideline contains one centre idea "to realize energy saving and pollution reduction", two preconditions "to guarantee high quality energy supply and ensure the communication open", and three key points "to save energy and water use, to protect the environment and to recycle the energy”. Meanwhile, energy management targets are closely related to energy management guideline. Actually, the energy management targets of Anyang Iron and Steel Enterprise in 2014 are to control comprehensive energy consumption per ton steel under 600kgce, new water consumption per ton steel under $3.7 \mathrm{m3}$, integrated power consumption per ton steel under $450 \mathrm{kwh}$ and annual energy output above 1.34 billion kwh. In order to achieve the targets, the enterprise decomposes them into more detailed goals and makes sure that each goal has its responsible person. Furthermore, strategies and solutions of energy management for all possible situation have been kept in paper to make sure the safety and efficiency of the energy management as well as realizing the guideline and targets.

Case analysis: Firstly, Anyang Iron and Steel Enterprise believes that energy saving means environmental protection and has pointed out to recycle more secondary energy and waste heat resources in its energy management guideline. Secondly, this guideline, related closely to the energy management targets and solutions, has continuous improvements and is easy to quantify decomposition. Thirdly, during the establishing of targets and detailed goals, Anyang Iron and Steel Enterprise has also taken technical, financial and operating requirements into consideration. Also, the enterprise emphasizes on commitment from top management and adjustment of the targets and detailed goals annually. In addition, Anyang Iron and Steel Enterprise has made detailed enterprise energy management strategies and solutions which specify the personnel in charge, detailed technical scheme, and implementation and evaluation methods. In conclusion, the combination among energy management guideline, targets and solutions in Anyang Iron and Steel Enterprise, which implies the power of plan management, the direction of the improvement and practical guidance, is a good pattern worthy learning by other iron and steel enterprises.

\subsection{Energy management structure of Anyang Iron and Steel Enterprise}

Case description: Energy and environmental protection department is the unique department in charge of energy management in Anyang Iron and Steel Enterprise. Apart from setting the responsible department, Anyang Iron and Steel Enterprise also implements three-levels governing and networked management after establishing the leading group consisted by enterprise top and middle management. In the networked management of energy management, all levels have to be responsible for their own duties according to different requirements and management permissions. 
The division of the duty, reward requirement, working standard have been kept in words to form the enterprise energy management policy. This energy management policy will be adjusted based on the actual practical situation and specialists are sent for supervision to ensure its implementation. Meanwhile, the evaluation for key indicators, the ability training for employees, and equipment maintenance are hold monthly, annually and on schedule respectively. It has also been found out that internal information exchange among management hierarchies are primarily through meetings such as schedule meeting or professional meeting. Energy utilization, target completion and work summary and arrangement are discussed in these meetings. Moreover, based on the information in the meetings, specialized personnel have been sent to participate in energy management structure improvement.

Case analysis: Three-levels and networked energy management structure on one side ensures the resources support from enterprise high hierarchy, on the other side, clears the management duties and permissions at all levels. This implies that regarded as one important part of the enterprise energy management system, construction of energy management structure connects the guideline and policy to the energy management practice. Also, this energy management structure forms its information communication mode through meetings (e.g. schedule meeting or professional meeting), ability training and target evaluation. In this sense, Anyang Iron and Steel Enterprise puts enterprise principles, targets and policies through the whole enterprise hierarchy and makes them realized in the production practice.

\subsection{Cultivation of energy-saving awareness in Anyang Iron and Steel Enterprise}

Case description: It is true that Anyang Iron and Steel Enterprise pays great attention to the cultivation of energy-saving awareness in energy management work resulting in a variety of measures such as energy saving propaganda and training, media education and study meeting. Generally, these measures are taken once or twice annually on schedule aiming to increase the energy-saving awareness in the whole enterprise. During the training, education and meeting, the potential consequences of deviating from energy policy and work rules are told to staffs to make sure that they notice the economic loss and security risk and have a better understanding of the enterprise rewords and punishment measures. Believed by Anyang Iron and Steel Enterprise, these measures can be very helpful to cultivate the energy saving awareness which leads to lower energy consumption, higher energy utilization efficiency and better performance of energy management.

Case analysis: The cultivation of energy-saving awareness in the enterprise is significant but also neglected easily. By increasing the energy-saving awareness, on one hand, Anyang Iron and Steel Enterprise makes employee nicely and correctly operate all kinds of equipments and reduce energy waste made by errors and incorrect use of energy; on the other, the enterprise combines guideline, targets and reward and punishment policy with employees' behavior and improves employees' positivity and creativity of energy -saving awareness in that awareness can have a huge influence on behavior. This indicates that Anyang Iron and Steel Enterprise recognizes the importance of cultivating energy-saving awareness and achieves good effect through measures such as energy saving propaganda and training, media education and study meeting. Nevertheless, there are still improving measures in cultivation of energy-saving awareness for Anyang Iron and Steel Enterprise to learn. For instance, Swedish Steel AB treats construction of energy-saving awareness as its company culture. Under this circumstance, measures like Hiring staffs with more energy conservation and environmental protection consciousness, improving working conditions to be suitable for energy saving, forming energy-saving groups and celebrating energy-saving achievements are taken into action(SSAB sustainable development report, 2013). All in all, the cultivation of energy-saving awareness in Swedish Steel AB is worth learning and thinking by Anyang Iron and Steel Enterprise to find its ways to improve energy-saving awareness.

\subsection{Energy management information system in Anyang Iron and Steel Enterprise}

Case description: As to energy information management, Anyang Iron and Steel Enterprise has established the enterprise energy management system (EMS) and set up an energy center. This energy management information system contains functions such as basic automation, process monitoring and optimal management. With real-time control and monitoring subsystem, it can also 
undertake energy monitoring works. Meanwhile, energy center based on this advanced computer technology aims to offer data analysis for assessment and decision-making and real-time online energy management. It can manage energy balance according to the scheduling optimization model embedded in EMS and forecast and plan the energy consumption through energy input-output model. However, due to the reason that this new energy management information system is now still in debugging stage, no data can be collected in this paper for the actual effect of the energy center to decrease energy consumption and increase energy efficiency.

Case analysis: The successful building of the energy management information system, which shows the ability to do real-time management, relates energy management work closely to specific production process. Yet, it also indicates the change of enterprise energy management mode. In this sense, Anyang Iron and Steel Enterprise should alter the energy management targets, policy and personnel assignment in accord with energy management information system. Hence, in order to make better use of energy management information system, one important work of energy management in the next phase is to adjust the energy management targets and specific process indexes on the basis of operation of energy center. Also, regular examination of the energy management information system should be done in case of the errors caused by the deviation between the computer modeling and practice situation. In brief, energy center management should be used with caution and shouldn't be the only dependence.

\subsection{Energy management in production process in Anyang Iron and Steel Enterprise}

Case description: The main production processes in Anyang Iron and Steel Enterprise contain five parts including coking process, sintering process, ironmaking process, steelmaking process and steel rolling process. (1) The energy consumption in coking process is $110 \mathrm{kgce} / \mathrm{t}$ (lower than national advanced standard $115 \mathrm{kgce} / \mathrm{t}$ ). During the production, coal blending and then crushing technology and coke dry quenching technology have been adopted. However, coal moisture control has not been used leading to about $11 \%$ moisture content, and raw coke-oven gas has been only reused for winter heating without recycling rising pipe gas. (2) The energy consumption in sintering process is 39kgce/t (lower than national advanced standard $45 \mathrm{kgce} / \mathrm{t}$ ). Anyang Iron and Steel Enterprise has taken hybrid pelletized sintering technology into use with main exhaust temperature of $150 \sim 400^{\circ} \mathrm{C}$ and recycled waste heat and residual gas heat in sintering machine cooling section. (3) The energy consumption in ironmaking process is $340 \mathrm{kgce} / \mathrm{t}$ (lower than national advanced standard $361 \mathrm{kgce} / \mathrm{t}$ ). To hot blast stove, air and gas preheating technology has been applied with blast temperature of $1100 \sim 1200^{\circ} \mathrm{C}$ and roof pressure of $230 \mathrm{kpa}$. Anyang Iron and Steel Enterprise also makes good use of oxygen-enriched coal injection technique and has adopted TRT (Blast Furnace Top Gas Recovery Turbine) technology and dry dust removal in ironmaking process. Besides, structural energy saving measures like controlling and adjusting the ration of iron and steel production are prepared for necessary situation. Yet, coal injection quantity can still be increased and CCPP technology can be adopted to generate more electricity. (4) The energy consumption in steelmaking process is negative $13 \mathrm{kgce} / \mathrm{t}$ (higher than national advanced standard negative 30kgce/t). It implies a good work for realizing negative energy steelmaking and huge potential for further reduction. By using converter steelmaking method, Anyang takes advantage of energy management information system in whole steelmaking process. But, recycle of converter energy is still low with converter gas recovery for $70 \mathrm{~m} 3 / \mathrm{t}$ and steam recovery for $80 \mathrm{~kg} / \mathrm{t}$.

Case analysis: By using technical, managerial and structural energy saving methods, Anyang Iron and Steel Enterprise has made abundant accomplishments in the production process level of energy management. Yet, there are still potentials and space for further improvements. For coking process, future development should focus on introduction of coal moisture control technology and increase the recycle of raw coke-oven gas. Meanwhile, technical energy saving measures should be combined with according managerial energy saving methods. As to sintering process, it is a good idea to adopt low temperature sintering technology and air leakage rate reduction technology and enhance the recycle rate of waste heat recovery in future energy management. To ironmaking process, coal injection can be further improved. Also, CCPP is not taken into use mainly due to high costs and low benefits. This indicates that adoption of energy saving technology should also 
consider the costs, risks and benefits before making final decision. When it comes to steelmaking process, the main reason of low converter gas recycle is space limitation. Old factories do not have enough space to reform for adoption of some energy saving technologies resulting in high energy consumption in steelmaking process. In steel rolling process, managerial measures should be laid more emphasis on. Through target management, plan management and policy management, increase of energy saving awareness, standardized operation and stable production can be achieved in order to make further improvement for energy saving. In general, only making full use of technical, managerial and structural energy saving methods together, can Anyang Iron and Steel Enterprise improve energy management effectively.

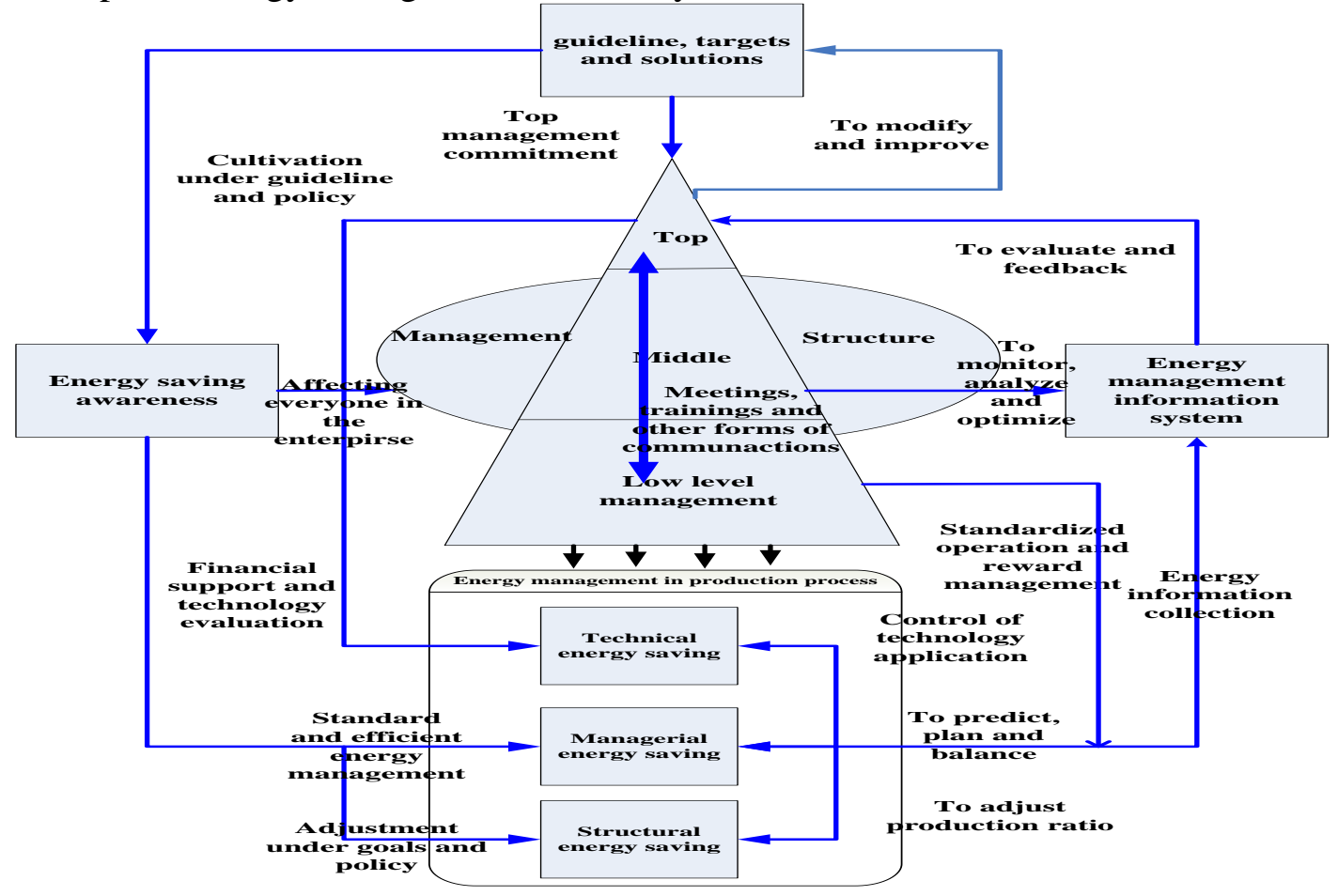

Figure 1. Energy management system in Anyang Iron and Steel Enterprise

\section{Summary and discussion of the case study}

According to case description and analysis, energy management system in Anyang Iron and Steel Enterprise is mainly composed of guideline, targets and solutions, energy management structure, cultivation of energy-saving awareness, energy management information system and energy management in production process. Figure 1 showcases the relationship and mechanism of interaction of these five subsystems. Actually, guideline, targets and solutions are made by enterprise top management and conveyed to enterprise's all levels through energy management structure. And then with the help of energy-saving awareness, technical, managerial and structural energy saving methods can be better functioned in energy management in production process. Later, based on data analysis and feedback made by energy management information system, performance evaluation of energy management and adjustment of guideline, targets and solutions can be implemented. In addition, guideline and targets are regarded as direction and solutions mean planning. This means to achieve energy saving purpose by plan management. Also, Seen as the foundation, energy management structure plays the role of organizational management through construction of communication and management channels combining targets and production practice together. Meanwhile, by turning the compulsive requirement into individual aspiration, cultivation of energy-saving awareness is really a good supplement and can be very helpful to adjust the employees' energy saving practice. Besides, energy management information system is suggested to be the center for data collection and analysis. Based on energy management information system, the enterprise can monitor, balance and optimize energy consumption and 
conduct energy-saving production. Moreover, energy management in production process is the key part of the whole system. The important thing in this subsystem is to make full use of technical, managerial and structural energy saving methods for controlling the energy consumption and realizing the energy saving purpose. In brief, indicated in figure 1, these five subsystems are closely linked with each other and constitute the whole energy management system in Anyang Iron and Steel Enterprise.

\section{Conclusions and Remarks of energy management}

According to case description, Anyang Iron and Steel Enterprise is at advanced level in the industry on multiple energy management performance indicators. Based on case analysis, Anyang Iron and Steel Enterprise attaches great importance to energy management with establishment of a relatively complete energy management system and integrated use of technical, managerial and structural energy saving methods. As a result, it can be said that Anyang Iron and Steel Enterprise has gain great achievements in energy management practice and these experiences can be of great help for other enterprise to learn from. Therefore, after overall consideration of gain and loss in Anyang Iron and Steel Enterprise energy management, this article summarizes these successful practical experiences into the following ten principles:

(1) Understand the complexity and systematicness of energy management;

(2) Find out all important influencing factors of enterprise energy management;

(3) Correctly set energy guideline and targets;

(4) Grasp the key points of building energy management structure;

(5) Cultivate energy awareness from corporate culture;

(6) Make full use of EMS and energy centre in energy information management;

(7) Technical method should be given first priority and comprehensively and thoroughly improve the application of energy saving technology;

(8) Managerial method is complementary and the enterprise should take advantages of various management measures to improve energy management performance;

(9) Structural method is supplement and plays an important role in adjusting and regulating;

(10) Enterprise energy management is a gradual process which needs to be adjusted and perfected constantly and should comprehensive use of five subsystems and three energy -saving methods.

\section{References}

[1] Brunke,et al., 2014. A plant-specific bottom-up approach for assessing the cost-effective EC potential and its ability to compensate rising energy-related costs in the German iron and steel industry, Energy Policy. pp.431-446.

[2] Caffall, C., 1995. Learning from experiences with energy management in industry, Centre for the analysis and dissemination of demonstrated energy technologies.

[3] Christoffersen, L B., Larsen, A., Togeby, M., 2006. Empirical analysis of energy management in Danish industry, Journal of Cleaner Production. 14(5), pp. 516-526.

[4] Cagno, E., Trianni, A., 2013. Exploring drivers for energy efficiency within small- and medium-sized enterprises: first evidences from Italian manufacturing enterprises, Appl. Energy. 104, pp.276-285.

[5] Kannan, R., Boie, W. 2003. Energy management practices in SME—case study of a bakery in Germany, Energy Conversion and Management. 44(6), pp.945-959.

[6] Norland, D L., Lind, L., 2001. Corporate energy management: A survey of large manufacturing companies, Energy engineering. 98(2), pp.53-72.

[7] Rohdin, P., Thollander, P., Solding, P., 2007. Barriers to and drivers for energy efficiency in the 
Swedish foundry industry, Energy Policy. .35, pp.672 -677.

[8] Rudberg, M., Waldemarsson, M., Lidestam, H., 2013. Strategic perspectives on energy management: A case study in the process industry, Applied Energy. 104, pp.487-496.

[9] Sivill, L., Manninen, J., Hippinen, I., Ahtila, P., 2013. Success factors of energy management in energy-intensive industries: development priority of energy performance measurement, Int. J. Energy Res. 37, pp.936 -951.

[10] Schultz, S C., Bingham, P R., 2000. 3M's Corporate Approach to Energy Management, 22 national industrial energy technology conference.

[11] SSAB Sustainability Report, 2013. http://www.ssab.com/ zh-CN/Sustainability/

[12] Thollander, P., Ottosson, M. 2008. An energy efficient Swedish pulp and paper industry e exploring barriers to and driving forces for cost-effective energy efficiency investments, Energy Efficient. 1, pp.21-34.

[13] Trianni, A., Cagno, E., Thollander, P., Backlund, S., 2013. Barriers to industrial energy efficiency in foundries: a European comparison, J. Clean. Prod. 40, pp.161 -176.

[14] Thollander, P., Danestig, M., Rohdin, P., 2007. Energy policies for increased industrial energy efficiency: evaluation of a local energy programme for manufacturing SMEs, Energy Policy. 35, pp.5774-5783.

[15] Wagner, M., 2009. Innovation and competitive advantages from the integration of strategic aspects with social and environmental management in European firms, Business Strategy and the Environment. 18(5), pp.291-306. 